\title{
Is the risk from nanomaterials perceived as different from the risk of 'chemicals' by the
} Australian public?

\section{Adam Caponn,b,d, Margaret Rolfec ${ }^{a}$, James Gillespie ${ }^{a}$ and Wayne Smith ${ }^{b}$}

a Menzies Centre for Health Policy, School of Public Health, University of Sydney, NSW, Australia

${ }^{b}$ Environmental Health Branch, Health Protection NSW, Sydney, Australia

c University Centre for Rural Health, School of Public Health, University of Sydney, NSW, Australia

${ }^{d}$ Corresponding author: acap1921@uni.sydney.edu.au

\section{Article history}

\section{Publication date: April 2016}

Citation: Capon A, Rolfe M, Gillespie J, Smith W. Is the risk from nanomaterials perceived as different from the risk of 'chemicals' by the Australian public? Public Health Res Pract. 2016;26(2):e2621618. doi: http://dx.doi.org/10.17061/ phrp2621618

\section{Key points}

- Nanomaterials are regulated as chemicals in Australia

- The Australian public perceives the risks from chemicals as greater than those from nanomaterials

- Those who have an aversion to chemicals are more likely to have an aversion to nanomaterials

- Communicating the safety of nanomaterials in terms of chemical safety may increase community angst towards nanomaterials

\begin{abstract}
Introduction: Manufactured nanomaterials in Australia are managed predominantly through existing chemical regulatory frameworks. Many regulators in Australia have suggested the framing of manufactured nanomaterials as 'chemicals' when communicating about manufactured nanomaterials to the general public. This paper aims to determine whether the Australian public perception of manufactured nanomaterials differs to that of chemicals, and to examine the relationship between attitudes towards chemicals and perceptions of nanomaterial risk.
\end{abstract}

Methods: We undertook a computer-assisted telephone interview survey of the Australian public. Analysis was undertaken using descriptive, paired tests of proportion, paired t-test and logistic regression techniques. We explored perceptions of nanomaterial risk and their relationship to perceptions of chemical risk and 'chemical attitudes'.

Results: We found that the public perceives nanomaterials in a more favourable light than it does chemicals. Perception of risk from chemicals had the greatest association with perceived nanomaterial risk (adjusted odds ratios between 0.1 and 0.2 ), and attitudes to chemicals were associated with perception of nanomaterial risk in some cases.

Conclusion: Risk communicators and policy makers need to consider the differences and associations between nanomaterials and chemicals when addressing the regulatory aspects of nanomaterials with the public. This is relevant for communication strategies that attempt to normalise the risks from nanomaterials compared with those of chemicals, especially as nanomaterials are perceived to be less risky than chemicals.

\section{Introduction}

Manufactured nanomaterials (nanomaterials) and 'chemicals' are considered one and the same by regulators in most cases. Nanomaterials are chemical substances that are manufactured at an extremely small scale, where 
each particle or unit of nanomaterial is typically less than 100 nanometres. ${ }^{1}$ This small size allows some nanomaterials to display different properties from their 'Iarger' form, and this can lead to unusual or unexpected health effects. ${ }^{2}$ Nonetheless, from a regulatory and policy perspective, nanomaterials are classified and assessed in the same way as chemicals, so that regulation of manufactured nanomaterials worldwide is done within frameworks set for chemical regulation. ${ }^{3-6}$

In Australia, the chemical regulation framework applied to nanomaterials involves distinct regulatory areas, five of which are the focus of this study:

- Food Standards Australia New Zealand, which regulates food

- Therapeutic Goods Administration, which regulates medicines and some sunscreens

- National Industrial Chemicals Notification and Assessment Scheme, which regulates some cosmetics and sunscreens

- Australian Pesticides and Veterinary Medicines Authority, which regulates pesticides

- Australian Competition and Consumer Commission, which regulates possible defects in consumer products that may contain nanomaterials, such as computers and tennis racquets.

Understanding public perceptions of risk from chemicals and how these perceptions drive or differ from perceptions of risk from nanomaterials is an important area of anticipatory research. ${ }^{7}$ Australian regulators of nanomaterials have suggested that nanomaterials should be framed as chemicals. ${ }^{8-10}$ It is important to determine the consequences that this framing may have on public perceptions.

A negative shift in public perception of risk from a novel technology can lead to a public backlash and foster mistrust of the government and its regulatory arms. This was seen when the European Union failed to anticipate public reaction to genetically modified foods. The result was a series of policy backflips that exacerbated public mistrust. ${ }^{11}$ Because of these potential negative consequences, it is useful for risk communicators and policy makers to understand the implications of framing nanomaterials as chemicals and comprehend the relationship between public attitudes towards chemicals and nanomaterials.

To explore public perceptions of risk from chemicals, and how these perceptions drive or differ from perceptions of risk from nanomaterials, our study included three aims. Our first aim was to examine whether public perception of risk from products identified as containing nanomaterials differed from identical products identified as containing chemicals. Our second aim was to explore whether those who perceived chemicals as a risk were more likely to perceive nanomaterials as a risk. Our third aim was to examine the association between the perceived risk from nanomaterials and three 'chemical attitudes': avoiding 'chemicals and chemical products in daily life'; believing 'the use of chemicals has helped us more than it has harmed us'; and considering whether 'chemicals are adequately regulated'. These three chemical attitudes were developed by Kraus et al. ${ }^{12}$ when exploring the cognitive models, assumptions and methods of inference that the public uses to assess risks associated with chemicals.

\section{Methods}

\section{Participation details}

In March 2013, we undertook a nationally representative cross-sectional household survey of adults, using computer-assisted telephone interviewing (CATI) landline and mobile phone technologies. Sampling was based on random selection from a stratified area probability sample of private dwellings and mobile phone users. All participants were recruited through random digit dialling. Sample weights accounted for the probability of selection, calibrated by age and sex (but not for jurisdictional strata) to the June 2012 Australian Bureau of Statistics (ABS) estimated resident population.

\section{Survey design and measures}

The questionnaire was developed from previous studies $^{13-15}$ and included cognitive testing on 10 random individuals of varying ages and gender, following ABS guidelines. ${ }^{16}$ Participants were given an introduction to nanotechnology and manufactured nanomaterials, which was presented in a neutral fashion to minimise bias. The primary outcome variables of interest for measuring public perception of 'manufactured nanomaterial risk' were based on responses to the questions: "Overall, in my opinion, manufactured nanomaterials are a risk to my health", "Overall, in my opinion, manufactured nanomaterials are a risk if they are put in the food I eat" and "Overall, in my opinion, manufactured nanomaterials are a risk if put into products such as (cosmetics and sunscreens) (medicines) (pesticides) (tennis racquets and computers)". The responses were categorised as 'agree strongly', 'agree', 'disagree' or 'disagree strongly'. The analysis collapsed these responses into a dichotomy of 'agree' or 'disagree', with 'don't know' and 'refused' responses removed. Respondents were asked to consider both risks and benefits when answering these questions. Other variables of interest from the public survey included basic demographics (age, sex), corresponding 'chemical risk', chemical attitudes and familiarity with nanotechnology.

Corresponding 'chemical risk' was determined in response to similar questions as for nanomaterials, where the term 'manufactured nanomaterials' was replaced with 'chemicals' in all six uses; for example, "Overall, in my opinion, chemicals are a risk to my health".

Chemical attitudes consisted of responses to the following questions: "I try hard to avoid chemicals and chemical products in my daily life" (described 
as 'avoid'); "The use of chemicals has improved our health more than it has harmed us" (described as 'improved'); and "I believe chemical risks are adequately regulated" (described as 'regulated'). Responses were categorised as 'agree strongly', 'agree', 'disagree' or 'disagree strongly', and analysed in a dichotomy of 'agree' or 'disagree', with 'don't know' and 'refused' responses removed.

Familiarity with nanotechnology was based on a composite of three questions: "Before today, had you heard of the term 'nanotechnology'?" (yes/no); if yes, "Have you ever talked about nanotechnology with anyone before today?" and "Have you ever searched for information about nanotechnology?" (yes, frequently; yes, occasionally; yes, only once or twice; no, never). No familiarity was based on a 'no' answer to the first question, moderate familiarity on a 'yes' answer to all questions, and some familiarity was the composite of the remaining answers.

Age was determined in response to "Would you mind telling me your age?" and categorised into seven age groups (18-24, 25-34, 35-44, 45-54, 55-64, 65-74 and $75+$ years).

The final survey instrument received ethics approval from the University of Sydney Ethics Committee (2012/1841).

\section{Statistical analysis}

Data were analysed using SAS software, with analyses corrected for weighting and stratified sample design to provide prevalence estimates. Statistical significance was determined at a $p$ value of $\leq 0.01$ to account for multiple comparisons.

To address our first aim, prevalence estimates of nanomaterial and chemical risk perceptions were analysed using the descriptive statistics of proportions and paired test of proportions.

To individually address aims two and three, unadjusted logistic regression models (using SurveyLogistic) were used to compare manufactured nanomaterial risk with chemical risk and the three chemical attitudes.

To assess aims two and three together, we used an adjusted logistic model, which compared 'manufactured nanomaterial risk' of each use (six) across the chemical risk variable and three chemical attitudes, with adjustments for age, sex and familiarity with nanotechnology. All variables were retained in adjusted logistic regression models as these variables were central to the purpose of the study. ${ }^{17}$ The Wald test was used to determine statistical significance, and significant effects are also indicated by confidence intervals for odds ratios that do not cross the value of 1 . For the independent variable, the category of 'agree' was used as the reference category.

\section{Results}

\section{Demographics}

The CATI survey was completed by 1355 Australian residents aged 18 years and older. A landline response rate of $34 \%$ and mobile response rate of $19 \%$ was calculated using American Association for Public Opinion Research standard calculations. The demographics of the weighted public survey population were comparable to June 2012 Australian population estimates for age, sex and residential state or territory.

\section{Prevalence of chemical attitudes}

Approximately $70 \%$ of the public tries to avoid chemicals and chemical products in daily life. The public is almost evenly split on whether chemicals have improved our health more than harmed it, and the adequacy of chemical regulations (Table 1).

Table 1. Public agreement regarding various chemical attitudes

\begin{tabular}{lcc}
\hline Chemical attitude & No. agreed & \% agreement $(99 \% \mathrm{Cl})$ \\
\hline Avoid & 987 & $71.8(67.8,75.9)$ \\
Improved & 658 & $52.8(48.3,57.4)$ \\
Regulated & 680 & $56.6(52.3,61.0)$ \\
\hline
\end{tabular}

$\mathrm{Cl}=$ confidence interval

\section{Comparison of public perception of chemical versus nanomaterial risk}

Table 2 ranks the prevalence of agreement of risk for the different uses of chemicals and manufactured nanomaterials. We found that the public considers foods containing either chemicals or manufactured nanomaterials to be the riskiest, and most uses of chemicals ranked higher in risk than manufactured nanomaterial usage, except for chemicals in medicines, tennis racquets and computers (Table 2). The difference between the chemical and manufactured nanomaterial perceptions by use were statistically significant for all uses except for cosmetics/sunscreens. Chemicals were perceived as riskier than manufactured nanomaterials for all uses except medicines. 
Table 2. Ranking of various chemical and nanomaterial uses by percentage public agreement of risk

\begin{tabular}{|c|c|c|}
\hline Use & No. agreed & $\%$ agreement $(99 \% \mathrm{Cl})$ \\
\hline Chemical (food) ${ }^{\star}$ & 1166 & $87.2(84.2,90.1)$ \\
\hline Nanomaterial (food) ${ }^{\star}$ & 1054 & $84.8(81.5,88.1)$ \\
\hline Chemical (health)* & 1015 & $78.2(74.7,81.8)$ \\
\hline Chemical (pesticide)* & 1034 & $78.1(74.3,81.8)$ \\
\hline $\begin{array}{l}\text { Chemical (cosmetics/ } \\
\text { sunscreen) }\end{array}$ & 962 & $72.7(68.7,76.8)$ \\
\hline $\begin{array}{l}\text { Nanomaterial } \\
\text { (cosmetics/sunscreen) }\end{array}$ & 913 & $72.2(68.0,76.4)$ \\
\hline $\begin{array}{l}\text { Nanomaterial } \\
\text { (medicine) }^{\star}\end{array}$ & 866 & $70.8(66.5,75.0)$ \\
\hline Nanomaterial (health)* & 798 & $65.7(61.1,70.3)$ \\
\hline $\begin{array}{l}\text { Nanomaterial } \\
\text { (pesticide) }^{*}\end{array}$ & 808 & $63.8(59.2,68.4)$ \\
\hline Chemical (medicine) ${ }^{*}$ & 759 & $59.3(54.8,63.7)$ \\
\hline $\begin{array}{l}\text { Chemical (tennis } \\
\text { racquet/computer)* }\end{array}$ & 640 & $46.0(41.5,50.5)$ \\
\hline $\begin{array}{l}\text { Nanomaterial (tennis } \\
\text { racquet/computer)* }\end{array}$ & 510 & $39.6(35.1,44.1)$ \\
\hline
\end{tabular}

${ }^{*}=p \leq 0.01$ between chemical and nanomaterial risk per use (e.g. food) using paired test of proportions; $\mathrm{Cl}=$ confidence interval

\section{Logistic regression analysis}

Tables 3 and 4 show the results of the unadjusted and adjusted logistic regression analysis of public perception of manufactured nanomaterial risk relating to chemical risk perception and chemical attitudes.

\section{Chemical risk perception}

Before and after adjusting for age, sex, chemical attitudes and familiarity with nanotechnology, the perception of chemicals as a risk remained significantly associated with perception of nanomaterials as a risk for all uses (Tables 3 and 4).

\section{Chemical attitudes}

All chemical attitudes were significant for all kinds of uses in the unadjusted analysis (Table 3), but the results were mixed after adjusting for age, sex, chemical risk perception, other chemical attitudes and familiarity with nanotechnology. Those who try hard to avoid chemicals and chemical products in their daily life are significantly more likely to perceive manufactured nanomaterials as a health risk as well as a risk if used in food, cosmetics/ sunscreens, medicines and pesticides. Those who do not agree that chemicals are adequately regulated are approximately twice as likely to believe that manufactured nanomaterials are a risk to health, and approximately twice as likely to believe that nanomaterials are a risk if put in cosmetics/sunscreens. Finally, believing that chemicals have improved our health more than they have created harm was not associated with any manufactured nanomaterials risk perceptions after adjustment (Table 4).

\section{Other variables}

Familiarity with nanotechnology remained significant after adjusting for all chemical attitudes, chemical risk perception, age and sex for all uses except food and pesticides. Age and sex did not remain significant after adjusting for all chemical attitudes, chemical risk perception, familiarity with nanotechnology, sex (in the case of age) and age (in the case of sex) (data not shown).

\section{Discussion}

Studies of public risk perceptions of nanomaterials have predominantly focused on how these perceptions are influenced by demographics, familiarity, trust and certain attitudes. ${ }^{7}$ Specifically, being male, young, white, educated, familiar with nanotechnologies and trusting of regulators have all been linked to lower risk perception of nanotechnologies. ${ }^{7}$ However, we are unaware of any publication that has examined the perceptions of nanomaterials and chemicals in the manner described in this study.

Table 3. Unadjusted odds ratios between public perception of manufactured nanomaterials risks and chemical variables

\begin{tabular}{lcccc}
\hline Use & Chemical risk (99\% Cl) & Avoid $(99 \% \mathrm{Cl})$ & Improved $(99 \% \mathrm{Cl})$ & Regulated $(99 \% \mathrm{Cl})$ \\
\hline Health & $0.1(0.1,0.2)$ & $0.2(0.1,0.4)$ & $3.0(1.9,4.7)$ & $3.4(2.2,5.3)$ \\
Food & $0.1(0.1,0.2)$ & $0.3(0.2,0.5)$ & $2.0(1.1,3.6)$ & $2.3(1.3,4.1)$ \\
Cosmetics/sunscreen & $0.1(0.1,0.2)$ & $0.3(0.2,0.5)$ & $3.6(2.2,5.7)$ & $3.8(2.4,6.1)$ \\
Medicines & $0.1(0.1,0.2)$ & $0.3(0.2,0.4)$ & $3.3(2.1,5.2)$ & $2.4(1.5,3.7)$ \\
Pesticides & $0.1(0.1,0.2)$ & $0.3(0.2,0.5)$ & $2.6(1.7,4.0)$ & $3.0(2.0,4.6)$ \\
Tennis racquet/computer & $0.1(0.1,0.2)$ & $0.4(0.2,0.6)$ & $2.1(1.4,3.1)$ & $1.9(1.3,2.8)$ \\
\hline
\end{tabular}

$\mathrm{Cl}=$ confidence interval

Note: Variable reference category = 'agree'; $p \leq 0.01$ for all uses and variables. 
Table 4. Adjusted odds ratios between public perception of manufactured nanomaterials risks and chemical variables

\begin{tabular}{lcccc}
\hline Use & Chemical risk $(99 \% \mathrm{Cl})$ & Avoid $(99 \% \mathrm{Cl})$ & Improved $(99 \% \mathrm{Cl})$ & Regulated $(99 \% \mathrm{Cl})$ \\
\hline Health & $0.2(0.1,0.3)^{*}$ & $0.4(0.2,0.7)^{\star}$ & $1.1(0.6,2.0)$ & $2.1(1.2,3.8)^{\star}$ \\
Food & $0.2(0.1,0.4)^{\star}$ & $0.5(0.2,0.9)^{\star}$ & $0.8(0.4,1.6)$ & $1.5(0.8,3.0)$ \\
Cosmetics/sunscreen & $0.2(0.1,0.3)^{*}$ & $0.6(0.3,1.0)^{*}$ & $1.6(0.9,2.8)$ & $2.3(1.3,4.0)^{\star}$ \\
Medicines & $0.2(0.1,0.3)^{\star}$ & $0.6(0.3,1.0)^{\star}$ & $1.7(1.0,2.9)$ & $1.5(0.8,2.4)$ \\
Pesticides & $0.2(0.1,0.3)^{\star}$ & $0.4(0.2,0.7)^{\star}$ & $1.3(0.8,2.2)$ & $1.7(1.0,2.9)$ \\
Tennis racquet/computer & $0.1(0.1,0.2)^{*}$ & $0.6(0.3,1.1)$ & $1.2(0.7,2.1)$ & $1.3(0.8,2.2)$ \\
\hline
\end{tabular}

${ }^{*}=p \leq 0.01$ after adjusting for other chemical risk or chemical attitudes, age, sex and familiarity with nanotechnology; $\mathrm{Cl}=\mathrm{confidence}$ interval Note: Variable reference category = 'agree'

In this study, we found that, overall, the general public perceives chemicals as riskier than nanomaterials, with the exception of their use in medicines. Therefore, should the public begin to equate nanomaterials with chemicals, our results indicate that nanomaterials - and nanotechnologies more generally - could suffer from a negative perception shift.

Although the first of its kind, our survey's results are not unexpected. Surveys of attitudes to nanotechnology and nanomaterials have found a predominantly benign view by the general public. When the public has been asked for examples of nanotechnology, it has elicited positive images of miniaturised products such as computers. ${ }^{18-20}$ In particular, an Australian survey found public perceptions of nanotechnology were focused on medical or implant devices; microtechnology/ miniaturisation; small robots; computing or computing components; and cosmetic or healthcare products. ${ }^{19}$ In contrast, public opinion surveys have found perceptions of substances defined as chemicals as predominantly negative. ${ }^{21,22} \mathrm{~A}$ survey of the Australian public found an overwhelmingly negative perception of chemicals, associating them with 'danger', 'medicines and drugs', 'pollution' and 'toxic'. ${ }^{21}$

The use of chemicals and nanomaterials in medicines defies this overall trend of chemicals being perceived as riskier than nanomaterials by the general public. It shows that the public has the capacity to differentiate between different uses of chemicals and nanomaterials, and their risks. A possible explanation for the perceptions relating to medicines could be the greater benefit:risk ratio the public sees from consuming medicines ${ }^{23}$, with this perceived benefit weighed against the uncertainty of nanomaterial use in medicines.

Chemical attitudes were associated with perceptions of risk from manufactured nanomaterials in some cases, particularly in people who avoid chemicals and chemical products in daily life. However, a negative risk perception of chemicals had the strongest association with a negative risk perception of nanomaterials - an association that was significant for all uses. In tandem, these results show that those sections of the public that have an aversion to chemicals are also likely to have an aversion to nanomaterials. This is significant because, if nanomaterials are perceived as chemicals in the future, the perception shift may not be as great as expected because of an already underlying association with chemical risk perceptions.

Our study contained a number of strengths. It was designed using randomised sampling for public responses, drawn from both landline and mobile technologies to ensure robust representation. Results were analysed with weighting and accounting for stratified sample design to estimate responses of the Australian population as a whole. The questionnaire was developed from previous surveys, with input and review from experts in the field, and was also cognitively tested. 'Chemical' risk questions and 'nanomaterial' risk questions were identical, with the exception of the words 'chemical' or 'nanomaterial', allowing direct comparison of the concepts. Finally, questions within topics were randomised to account for ordering effects.

The study also has a number of limitations.

Measurement bias may have been introduced if those who responded to our study were statistically different from those who declined to participate. In an anonymous CATI survey, it is not possible to contact those who refused to participate to determine this bias. Collapsing responses from a four-point scale (agree strongly, agree, disagree, disagree strongly) to a two-point scale (agree or disagree) reduced the ability to analyse the range of attitudes; however, we were primarily interested in the two-point response.

This research is a first step in providing evidence regarding the impact that chemical perceptions and attitudes have on the risk perception of nanomaterials. Further research using a comprehensive suite of chemical attitudes is required to develop intuitive toxicological personalities, and to explore how these defined personality types perceive risks from nanomaterials. Undertaking this research would support targeted risk communication strategies. 


\section{Conclusion}

The public currently views nanomaterials in a more favourable light than chemicals. Therefore, if the public begins to perceive nanomaterials as chemicals, nanomaterials (and nanotechnologies more broadly) could suffer from a negative image shift, with the exception of their application to medicines. Members of the public who have negative attitudes towards chemicals or perceive chemicals as a risk are more likely to perceive nanomaterials as a risk, suggesting that some sectors of the public view nanomaterials and chemicals as similar risk entities. Risk communicators should be aware of these disparities and associations, and understand that, when communicating about the regulatory systems in place to protect human health, this may increase public angst towards nanotechnologies.

\section{Competing interests}

None declared

\section{Author contributions}

All authors made substantial contributions to the intellectual content of the manuscript. AC provided concept and design, acquisition of data, analysis and interpretation of data. MR provided data analysis and interpretation of data. JG provided concept and design, and interpretation of data. WS provided expertise in concept and design. All authors participated in drafting the manuscript, including review and final approval.

\section{References}

1. European Commission. Environment. Nanomaterials. Brussels: European Commission; 2015 [cited 2016 Feb 16] [about 2 screens]. Available from: ec.europa.eu/environment/chemicals/nanotech/index_ en.htm

2. Editorial. The dose makes the poison. Nat Nano. 2011;(6):329.

3. Capon A, Smith W, Gillespie JA. Navigating public health chemicals policy in Australia: a policy maker's and practitioner's guide. N S W Public Health Bull. 2013;23(12):217-27

4. European Commission. Environment. Nanomaterials in REACH and CLP. Brussels: European Commission; 2014 [cited 2014 Oct 17] [about 2 screens]. Available from: ec.europa.eu/environment/chemicals/nanotech/reach-clp/ index_en.htm
5. US Environmental Protection Agency. Control of nanoscale materials under the Toxic Substances Control Act. Washington, DC: US Environmental Protection Agency; 2015 [cited 2014 Oct 17] [about 7 screens]. Available from: www.epa.gov/reviewing-new-chemicalsunder-toxic-substances-control-act-tsca/controlnanoscale-materials-under

6. US Food and Drug Administration. Guidance for industry: safety of nanomaterials in cosmetic products. Silver Spring, MD: US Food and Drug Administration; 2014 [cited 2014 Jan 17] [about 20 screens]. Available from: www.fda.gov/Cosmetics/GuidanceRegulation/ GuidanceDocuments/ucm300886.htm

7. Satterfield T, Kandlikar M, Beaudrie C, Conti J, Herr Harthorn B. Anticipating the perceived risk of nanotechnologies. Nat Nano. 2009;4(11):752-8.

8. Australian Pesticides and Veterinary Medicines Authority. Nanotechnologies for pesticides and veterinary medicines: regulatory considerations. Final report. Canberra: Australian Pesticides and Veterinary Medicines Authority; 2015 [cited 2016 Mar 15]. Available from: apvma.gov.au/sites/default/files/publication/15626nanotechnologies-pesticides-veterinary-medicines_ regulatory-considerations_july2015.pdf

9. Fletcher N, Bartholomaeus A. Regulation of nanotechnologies in food in Australia and New Zealand. International Food Risk Analysis Journal. 2011;1(2):33-40.

10. National Industrial Chemicals Notification and Assessment Scheme. Our approach to regulating industrial nanomaterials. Canberra: Department of Health; 2015 [cited 2015 Sep 14]. Available from: www. nicnas.gov.au/communications/issues/nanomaterialsnanotechnology/our-approach-to-regulating-industrialnanomaterials

11. Vogel D. The politics of precaution: regulating health, safety, and environmental risks in Europe and the United States. Princeton, NJ: Princeton University Press; 2012.

12. Kraus N, Malmfors T, Slovic P. Intuitive toxicology: expert and lay judgments of chemical risks. Risk Analysis. 1992;12(2):215-32.

13. IPSOS Social Research Institute. Community attitudes towards emerging technology issues - nanotechnology. Canberra: Australian Government Department of Industry Innovation Science Research and Tertiary Education; 2012 [cited 2016 Mar 15]. Available from: www.industry. gov.au/industry/IndustrySectors/nanotechnology/ Publications/Documents/Emergingtechstudynano.pdf

14. Retzbach A, Marschall J, Rahnke M, Otto L, Maier M. Public understanding of science and the perception of nanotechnology: the roles of interest in science, methodological knowledge, epistemological beliefs, and beliefs about science. J Nanopart Res. 2011;13(12):6231-44. 
15. TNS Opinion \& Social. Special Eurobarometer: biotechnology. Brussels: European Commission; 2010 [cited 2016 Mar 15]. Available from: ec.europa.eu/public_ opinion/archives/ebs/ebs_341_en.pdf

16. Statistical Clearing House. Pre-testing in survey development: an Australian Bureau of Statistics perspective. Canberra: Australian Bureau of Statistics; 2001 [cited 2016 Mar 15]. Available from: www.nss.gov. au/nss/home.NSF/75427d7291fa0145ca2571340022a2 ad/906dca4c30eac6aeca2571ab0024717c/\$FILE/PreTesting\%20in\%20Survey\%20Development.pdf

17. Agresti A, Kateri M. Categorical data analysis. International Encyclopedia of Statistical Science. Berlin: Springer; 2011.

18. Hays S, Miller C, Cobb M. Public attitudes towards nanotechnology-enabled cognitive enhancement in the United States. In: Hays SA, Robert JS, Miller CA, Bennett I, editors. Nanotechnology, the brain, and the future: 3 (yearbook of nanotechnology in society). Dordrecht: Springer Netherlands; 2013. 43-65.

19. Market Attitude Research Services. Australian community attitudes held about nanotechnology - trends 2005 to 2011. Australian Government Department of Industry Science and Research; 2011 [cited 2016 Mar 15]. Available from: www.industry.gov.au/industry/ IndustrySectors/nanotechnology/Publications/Documents/ NanotechnologyPublicAwareness2011.pdf
20. Zimmer R, Hertel R, Boi G-F. Public perceptions about nanotechnology - representative survey and basic morphological-psychological study. Berlin: Federal Institute for Risk Assessment; 2008 [cited 2016 Mar 15]. Available from: www.bfr.bund.de/cm/350/public_ perceptions_about_nanotechnology.pdf

21. Starr G, Langley A, Taylor A. Environmental health risk perception in Australia - a research report to the Commonwealth Department of Health and Aged Care. Adelaide: South Australian Department of Human Services; 2000.

22. TNS Opinion \& Social. Special Eurobarometer 360: consumer understanding of labels and the safe use of chemicals. Brussels: European Commission; 2011 [cited 2016 Mar 15]. Available from: ec.europa.eu/public_ opinion/archives/ebs/ebs_360_en.pdf

23. Slovic P. Perception of risk. Science. 1987;236(4799):280-85.

\section{Copyright: (c) (i) (2)}

(C) 2016 Capon et al. This article is licensed under the Creative Commons Attribution-NonCommercial-ShareAlike 4.0 International Licence, which allows others to redistribute, adapt and share this work non-commercially provided they attribute the work and any adapted version of it is distributed under the same Creative Commons licence terms. See: www.creativecommons.org/licenses/by-nc-sa/4.0/ 